\title{
EXPLORING THE ROLE OF DISTRIBUTED LEARNING IN DISTANCE EDUCATION AT ALLAMA IQBAL OPEN UNIVERSITY: Academic Challenges at Postgraduate Level
}

\author{
Qadir BUKHSH \\ Assistant Professor \\ Department of Educational Training \\ The Islamia University of Bahawalpur, PAKISTAN \\ Dr. Muhammad Ajmal CHAUDHARY \\ Assistant Professor/ Chairman \\ Department of Distance, Non-Formal and Continuing Education \\ Allama Iqbal Open University Islamabad, PAKISTAN
}

\begin{abstract}
Distributed learning is derived from the concept of distributed resources. Different institutions around the globe connected through network and the learners are diverse, located in the different cultures and communities. Distributed learning provides global standards of quality to all learners through synchronous and asynchronous communications and provides the opportunity of flexible and independent learning with equity, low cost educational services and has become the first choice of the dispersed learners around the globe. The present study was undertaken to investigate the challenges faced by the Faculty Members of Department of Business Administration and Computer Science at Allama Iqbal Open University Islamabad Pakistan. 25 Faculty Members were taken as sample of the study from both Departments (100\% Sampling). The study was qualitative in nature and interview was the data collection tool. Data was analyzed by thematic analysis technique. The major challenges faced by the Faculty Members were as: bandwidth, synchronous learning activities, irregularity of the learners, feedback on individual work, designing and managing the learning activities, quality issues and training to use the network for teaching learning activities.
\end{abstract}

Keywords: Distributed learning, Faculty challenges, Allama Iqbal Open University, web-based learning, flexible learning, network learning

\section{INTRODUCTION}

Distributed Learning is synonymously used with open learning, distance learning, flexible learning, individualized learning, blended learning, web-based learning, network learning, off campus learning and online/ e-learning but the key feature of the term is the diversity of the resources, students, campuses and multi-location teaching around the globe. The development of the modern communication technology and internet has enabled explosive growth and changed the perspectives of educational opportunities and practices. The electronic education has supported all forms of the education particularly the novel world of learning is opening the gates through the web-based distributed learning. Distributed education models are emerging 
as new technologies, tools and research findings become available in higher education. Different methodologies emerged as the result of growth of network education in distributed learning. New patterns of E-pedagogy and E-assessment which have progressively become more pervasive elements at higher education level emerged as web-based distributed learning has become more wider spread to facilitate all levels of the population (Barik. N \& Karforma. S. D, 2012; Dutta. K. A et. al, 2011; Verdu. E. et. al, 2012) The concept of the distributed learning comes from the distributed resources. It is an instructional model that allows teachers, students and the content to be located in non-centralized different locations.

In this instructional model the instruction occur independent of the time and the place. The distributed learning may be implemented according the need; it can be used to create a virtual classroom with the use of technology or with the combination of the traditional distance learning course (Ciftci. S et. al, 2010).Distributed learning is associated with information technologies, computers, web-based learning and virtual learning and use of modern communication tools and techniques to facilitate learner and effective outcome of the process.

It is an instructional model that involves the use of information technologies to facilitate the remote access. It is known as the computer mediated instruction which uses the video and audio conferencing, satellite broadcasting, web-based multimedia formats and specially designed techniques and methodologies (Cornell University Library, 2013).

(Mahfouth.A ,2012; Barik.N\&Karforma.S.D, 2012; Ahmad. I \&Bokhari. U. M, 2013) argued Using the modern communication tools and techniques, the distributed learning has become the most used and popular technique to address the spread clientele. Distributed learning provides the opportunity to create the new community of the universities around the globe sharing best practices and the pedagogical innovations by using the interactive e-learning technologies locating in the different parts of the world. The dramatic changes in higher education are associated with the distributed learning innovative techniques and methodologies. The internet meets the growing demand of interactive communication, advance study material and all the modern resources for the effective learning. Due to the advance technology the communications become very fast and these fast communications can be applied to the field of education for convenience and for faster services.

Universities are using and promoting the distributed learning approaches for staff development, technical training and other teaching learning activities. There is verity of the ways to execute the distributed learning; it is consistent in that it always accommodates the separation of geographical location for part or all of the instruction. It always focus learner to learner and instructor to learner communications for the successful educational process. There exist a verity in the delivery model of the distributed learning; it includes web-based instructions, streaming of video conferencing, audio conferencing, electronic resources and satellite broadcasts (Kaewkiriya, 2013).

The main purpose of designing distributed learning system is to speed up the learning as compared to the non-distributed system. The use of synchronous and asynchronous learning gain popularity in the delivery of the content at higher education level. In the last decade, the development of the electronic devices like smart phones, iPods, tablets, net books etc and internet has changed the delivery mechanism of instructional process. The synchronous learning is the live interaction and requires pre-organization of the time table. The media used in synchronous learning is video conferencing, instructional television, live streaming and live chat. Asynchronous learning or network learning is also an effective model in distributed 
learning, the media included is email, voice mail, audio and video recordings. In asynchronous learning participants can access to the course material with their own schedule and the time available to them. Learners can download the material according to their capacity and need and complete their assignments by using the asynchronous model (Mshvidobadze.T\&Gogeladze.T, 2012; Xenos.M et.al, 2009).

According to (Baker.J.D\&Zuvela.D, 2013; Liu.Z.G, 2012; Valle.D.R\&Duffy.M.T, 2009) Distributed learning technologies are widely used to cater the needs of the scattered students in different localities as their learning needs are addressed by the use of the technology.

The key feature of the distributed learning is flexibility which uses the special design, methodologies, technologies, instructional techniques, tools, communication methodologies and arrangements.

Many students are attracted to the distributed learning because of the freedom and the flexibility in managing their learning activities.

They have the freedom of the decision making about their studies.

The schedule, time and place all have flexibility in distributed learning.

Students have access to educational opportunities, connectivity and flexibility to promote their learning in the flexible environment of the distributed learning environment.

The freedom of the choice of the courses is another attraction to the learners as they may select the courses according to the time available to them, cost of the courses and the capacity of the learners in the relevant area of the course.

\section{OBJECTIVES OF THE STUDY}

Following were the objectives of the study:

$>$ To explore the potential role of distributed learning in Distance Education

$>$ To investigate the challenges faced by the Faculty in distributed learning at Allama Iqbal Open University

$>$ To suggest initiatives to solve the challenges and problems faced by Faculty in distributed learning at Allama Iqbal Open University

\section{RESEARCH METHODOLOGY}

The study was qualitative in nature. Data was collected through a semi structured interview schedules from respective Faculty Members of the Department of Business Administration and Computer Sciences at Allama Iqbal Open University Islamabad, Pakistan.

All (25) Faculty Members of the Department of Business Administration and Computer sciences involved in distributed teaching learning in the programmes of MBA (Col) and PGD online programmes were taken as sample respectively of Allama Iqbal Open University Islamabad, Pakistan (100\% sampling) 


\section{DATA ANALYSIS}

NVivo10 was used for the qualitative thematic data analysis of the interviews of the Faculty Members of the Department of the Business Administration and Computer Science at Allama Iqbal Open University.

The thematic data analysis of the interviews of the Faulty Members is given:

Graph 1 explains that there were twenty five faculty members participated in this study. $64 \%$ Faculty Members participated from Department of Business Administration, 36\% were from Department of Computer Sciences were interviewed at Allama Iqbal Open University.

Graph 1

Departmental Profile of Faculty

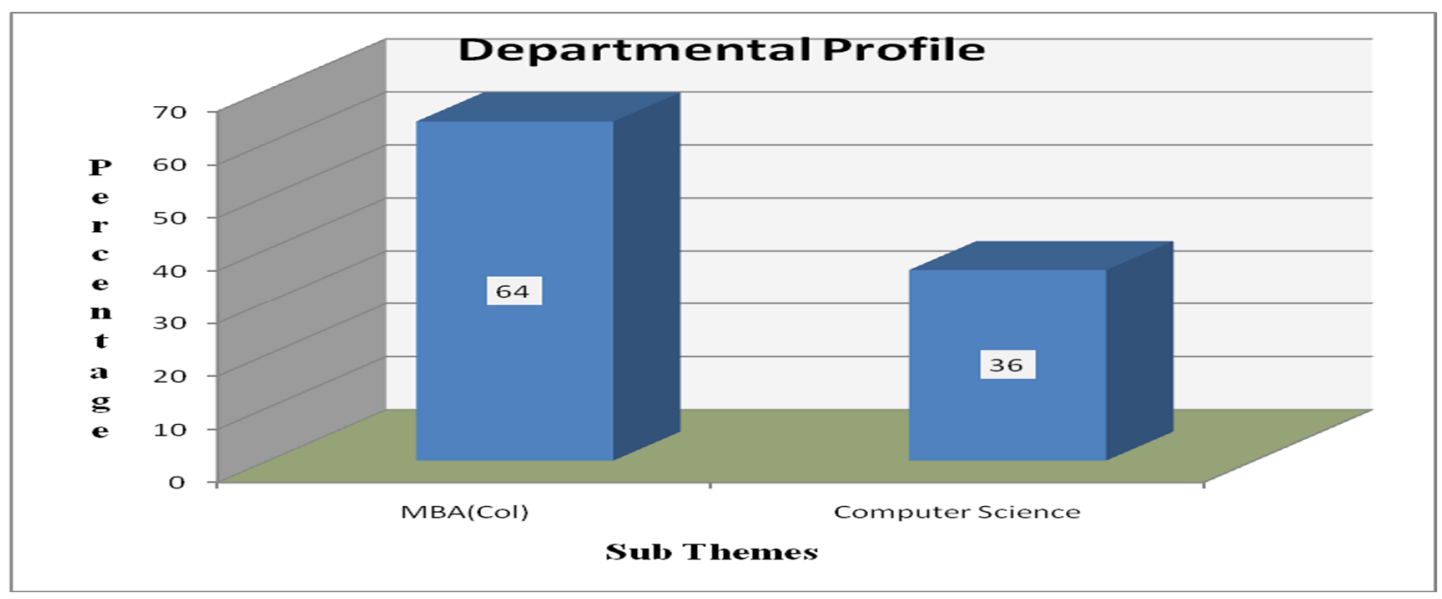

Q 1: What hurdles do you face due to the organizational policies in teaching leaning activities in online teaching?

Graph 2 points out that majority $(64 \%)$ of respondents commented that they faced no hurdles due to the organizational policies for distributed learning at Allama Iqbal Open University. 44\% of the respondents mentioned that AIOU pay low remunerations for online delivery of the lectures. $\mathbf{4 0} \%$ of the respondents indicated that the organizational policies were facilitating and $32 \%$ said that organizational policies were supporting. Only $28 \%$ of the respondents gave opinion that they faced hurdles due to organizational policies for distributed learning in both Departments of Computer Sciences and Business Administration respectively at AIOU. 
Graph 2

Percentage of the respondents on hurdles of the Organizational Policies

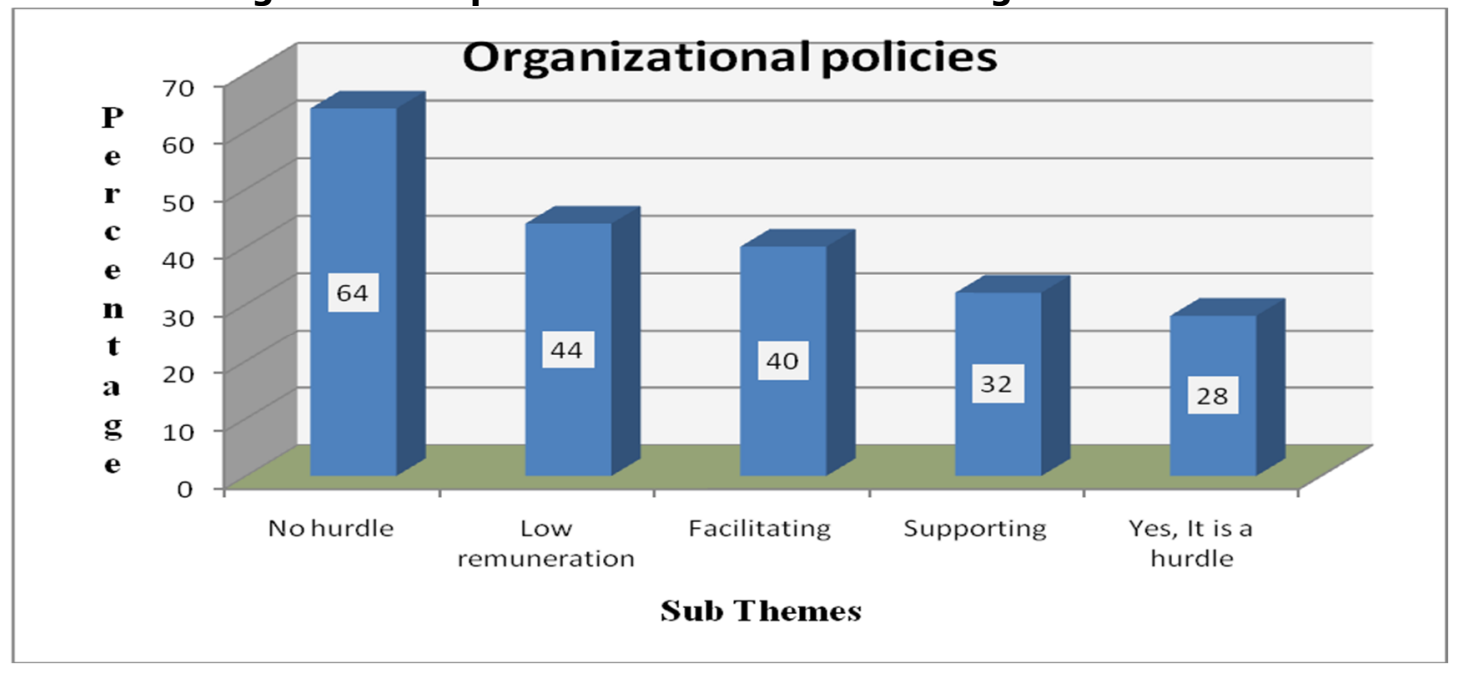

Q 2: Do you think that your teaching is affected due to bandwidth of internet?

Graph 3 shows that significant majority $(96 \%)$ of respondents reported thatbandwidth is a challenge for them at institution level and significant majority $(88 \%)$ faced challenge in video sharing for distributed learning at Allama Iqbal Open University. Majority (80\%) of the respondents viewed that bandwidth was the biggest challenge at user end level and majority $(64 \%)$ suggested that they faced challenges of remote access due to low bandwidth of internet. Only52\% of the respondents informed that they encountered net failure due to low bandwidth of internet for distributed learning at AIOU.

\section{Graph 3}

Percentage of the respondents on bandwidth of internet

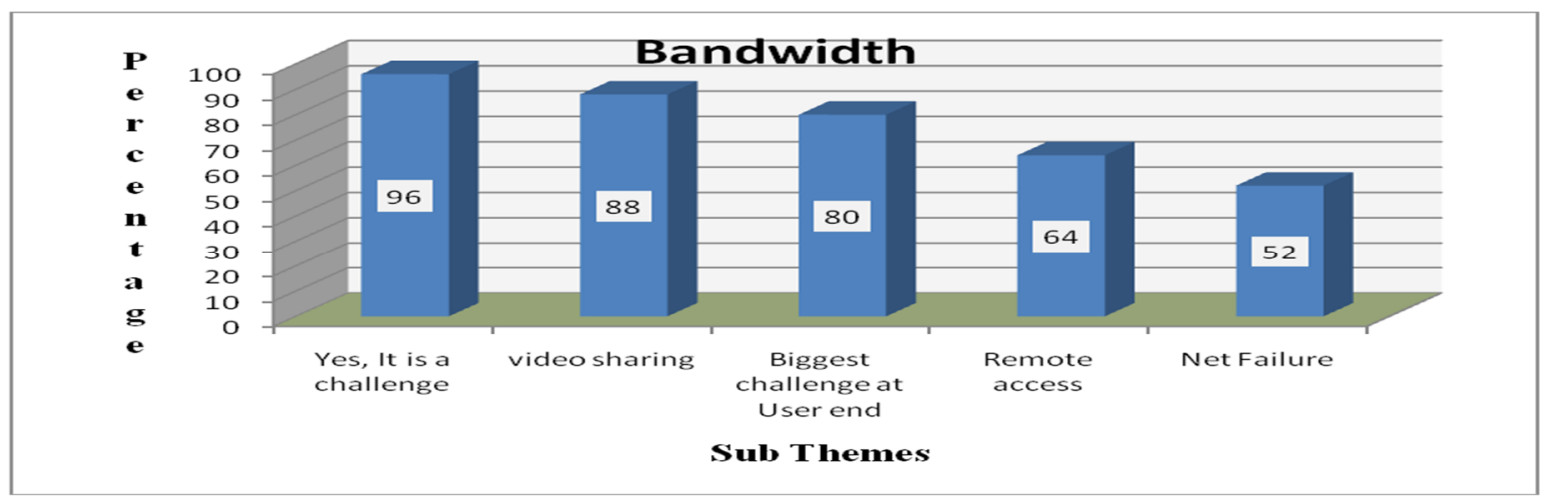

Q 3: What challenges you face to implement synchronous and asynchronous teaching learning activities at your network?

Graph 4 indicates that significant majority $(96 \%)$ of respondents commented that synchronous and asynchronous teaching learning activities need improvement and $(88 \%)$ said that synchronous teaching learning activities was challenge for them no challenge for asynchronous teaching learning activities for distributed learning at Allama Iqbal Open University. $76 \%$ of the respondents faced the video sharing challenge and $60 \%$ of the 
respondents suggested that distributed learning required virtual learning environment to implement distributed learning at AIOU.

\section{Graph 4}

Percentage of the respondents on synchronous and asynchronous teaching learning activities at network

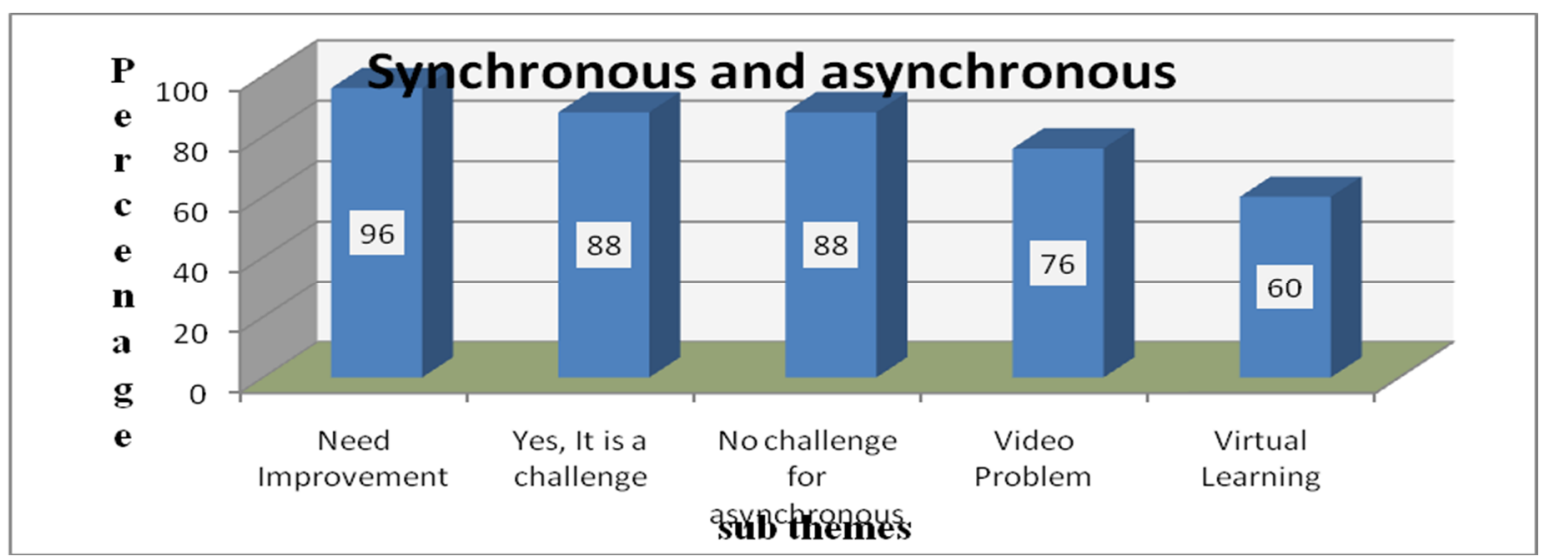

Q 4: Do you face technology challenges in teaching learning through distributed learning? Graph 5 highlights that significant majority $(84 \%)$ of respondents mentioned that technological challenges existed for distributed learning at Allama Iqbal Open University and $72 \%$ of the respondents viewed that technical skills were required at the user end. $68 \%$ of the respondents explained that there existed usability challenge at the user end and $64 \%$ indicated that computer skill was required both at institution and user end level. $48 \%$ of the respondents presented that training of the students is required to overcome the technological challenges to implement the distributed learning at AIOU.

\section{Graph 5}

\section{Percentage of the respondents on technology challenges}

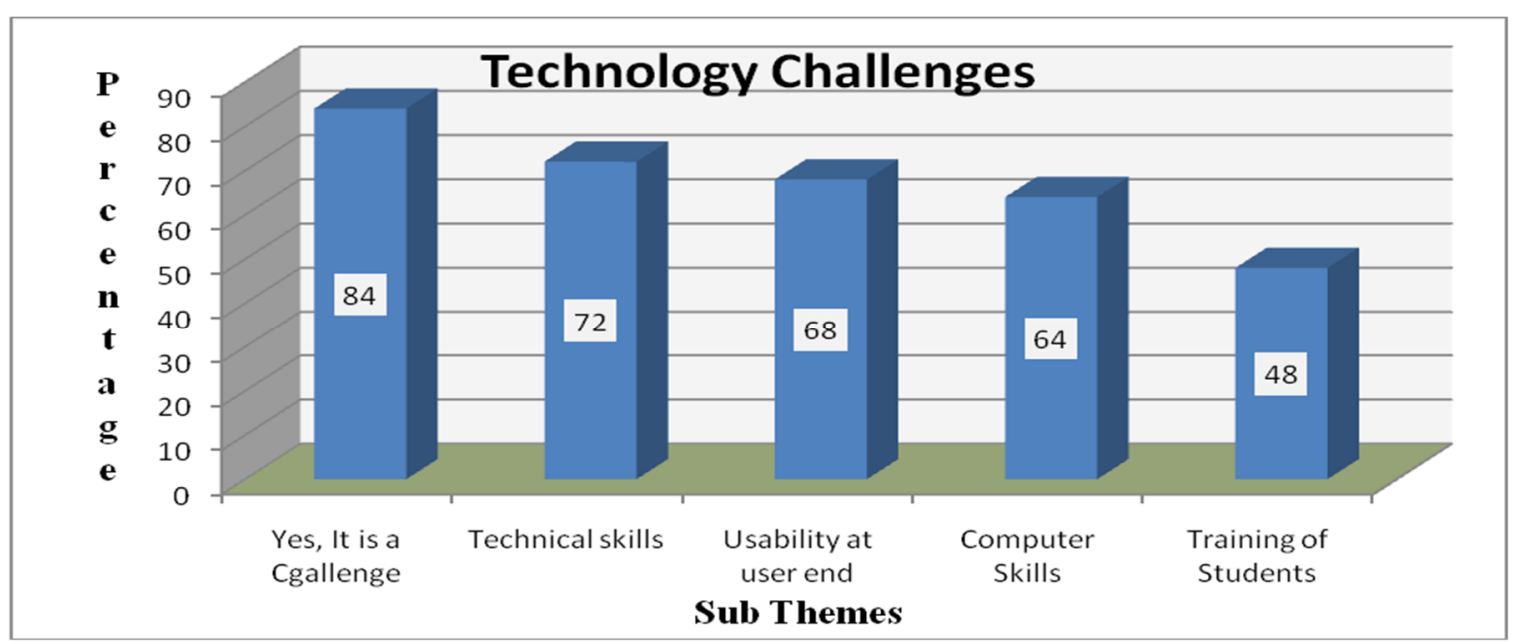


Q5. What challenges you face in instructional delivery in online teaching?

Graph 6 presents that majority $(76 \%)$ of respondents reported the irregularity of the students, they logged on and logged off suddenly and (72\%) of the respondents commented that students need training to use the network. $68 \%$ of the respondents viewed that effective online delivery need more organization of the lecture and $56 \%$ indicated that delivery of lecture in distributed learning need more preparation. $52 \%$ of the respondents explained that focused approach is needed for distributed learning on the network at AIOU.

Graph 6

Percentage of the respondents on Instructional delivery challenges

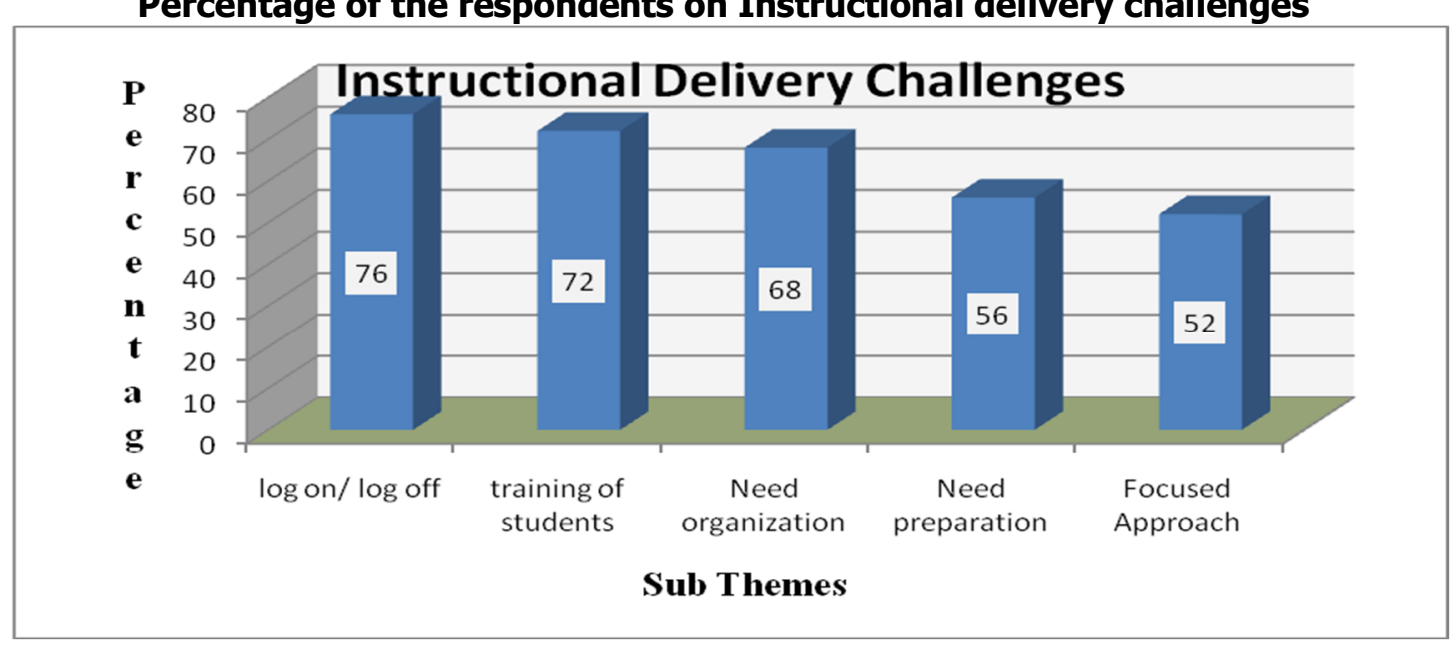

Q 6: Which type of problems do you face in online assessment and feedback to your students? Graph 7 imparts that $68 \%$ of respondents revealed that provision of the feedback on individual work is a challenge and $64 \%$ agreed that provision of feedback was a challenge and students submitted copied work. $56 \%$ of the respondents reported that students' submission was not on time and only $36 \%$ of the respondents said the online assessment and feedback to the students in distributed learning at AIOU was not challenge for them.

\section{Graph 7}

Percentage of the respondents on online assessments and feedback

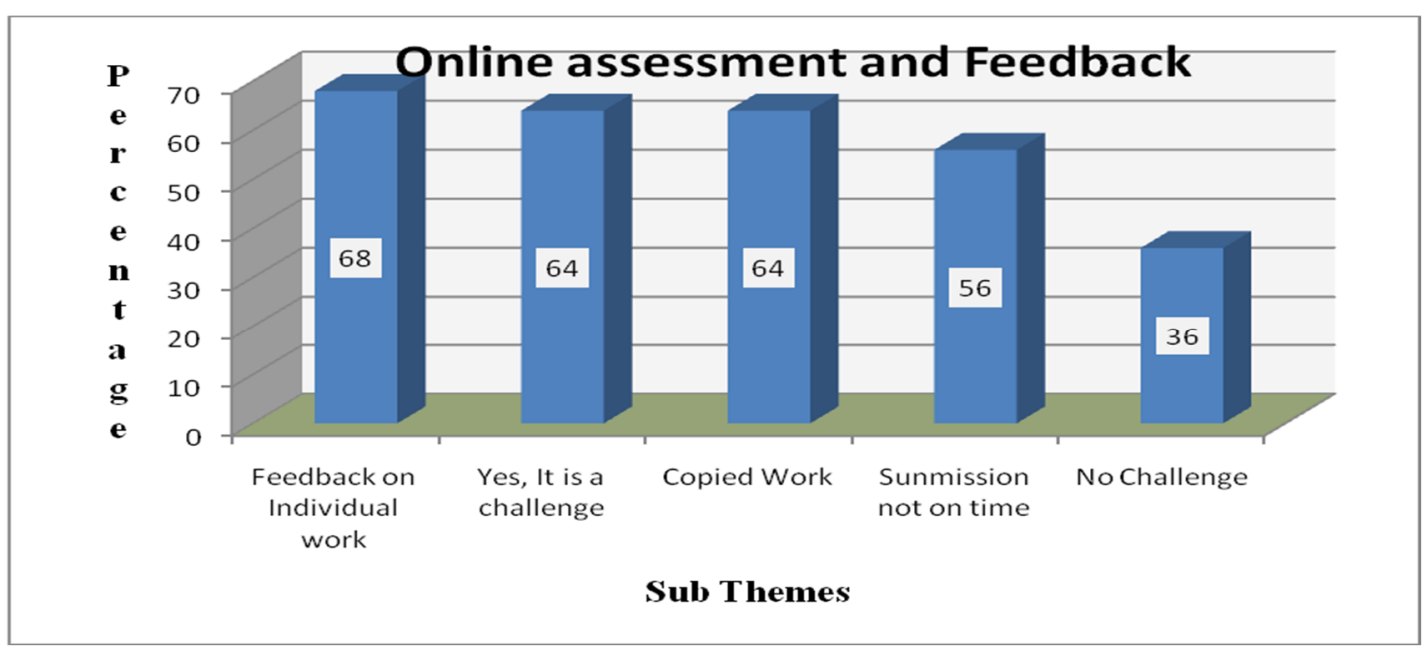


Q 7: What challenges do you face due to pedagogical issues in online delivery?

Graph 8 argues that majority $68 \%$ of respondents commented that designing of the lecture and materials were challenges and $52 \%$ respondents informed that file sharing was challenge. $44 \%$ of the respondents said that designing project work was challenge and only $36 \%$ of the respondents explained that use of white board was a one of the challenge in distributed learning at AIOU.

\section{Graph 8}

Percentage of the respondents on pedagogical issues in online delivery

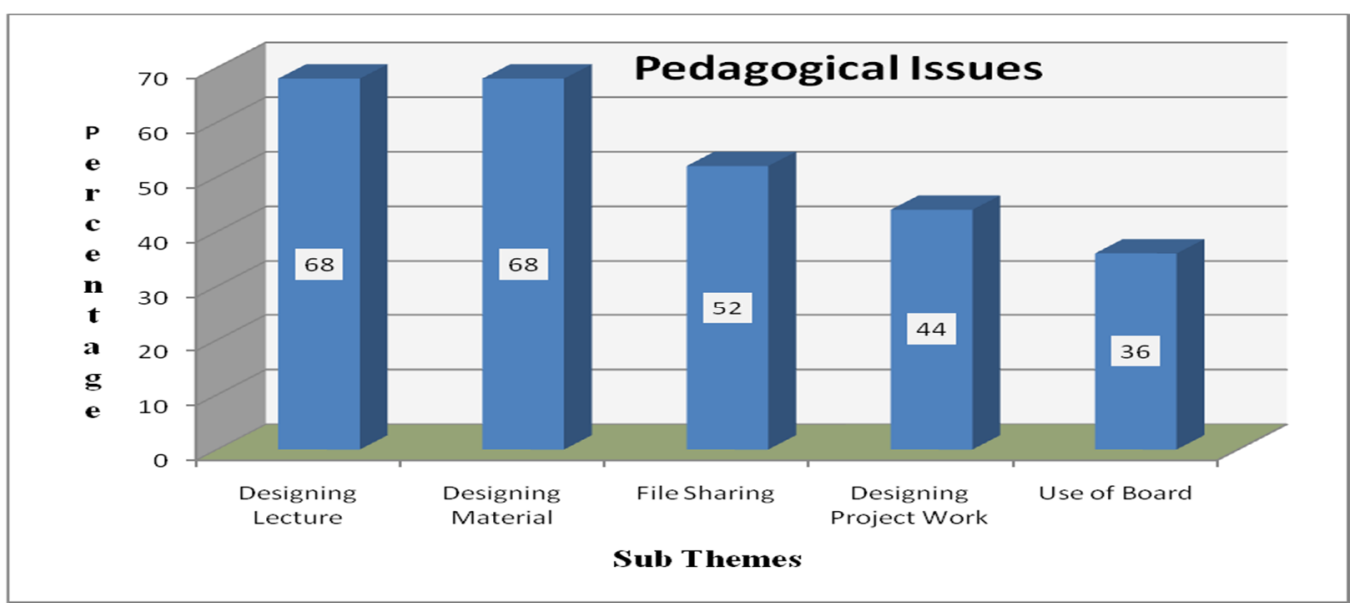

Q 8: Are you satisfied with the teaching

learning environment of distributed learning in your institution?

Graph 8 mentioned that significant majority (100\%) of respondents commented that energy failure was one of the key challenge and $(96 \%)$ of the respondents indicated that teaching learning environment need improvement at Allama Iqbal Open University. Majority (88\%) viewed that bandwidth was a challenge. $68 \%$ of the respondents said that video sharing was a challenge and only $44 \%$ of the respondents informed that virtual environment was required for distributed learning at AIOU.

\section{Graph 9}

Percentage of the respondents on teaching learning environment

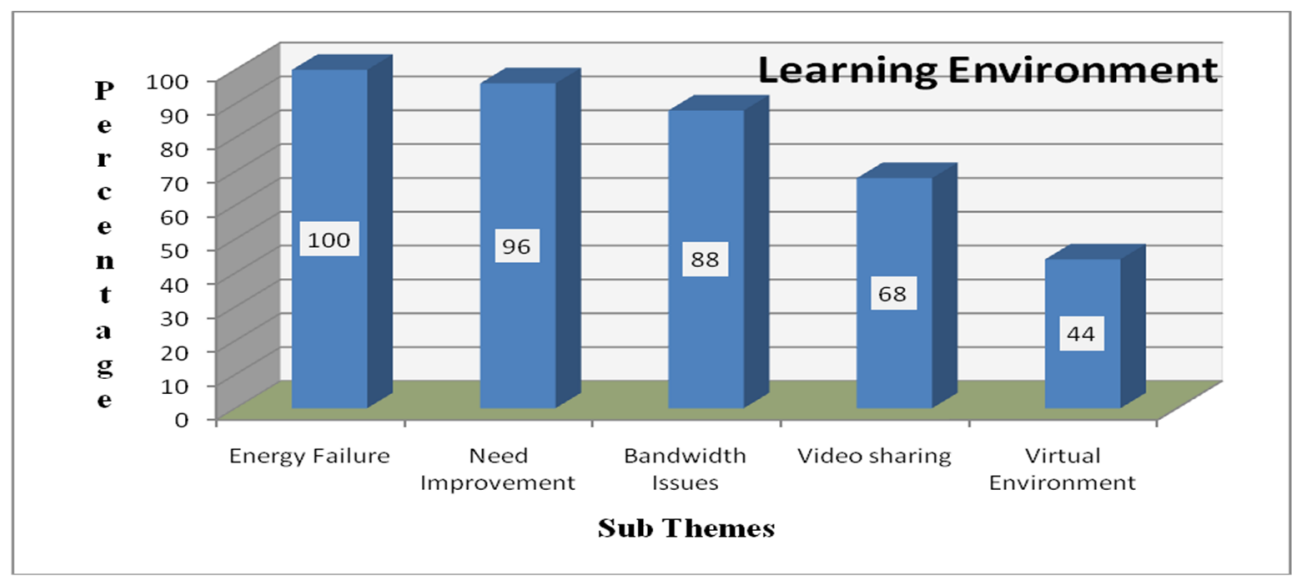


Q 9: Do you think that security issues are major challenges

in you institution through online teaching?

Graph 9 points out that significant majority $(100 \%)$ of respondents commented that there was no challenge of security as there was no e-exam and (84\%) of the respondents explained that institution provided privacy to the data of the students in distributed learning at AIOU.

\section{Graph10}

Percentage of the respondents on security issues

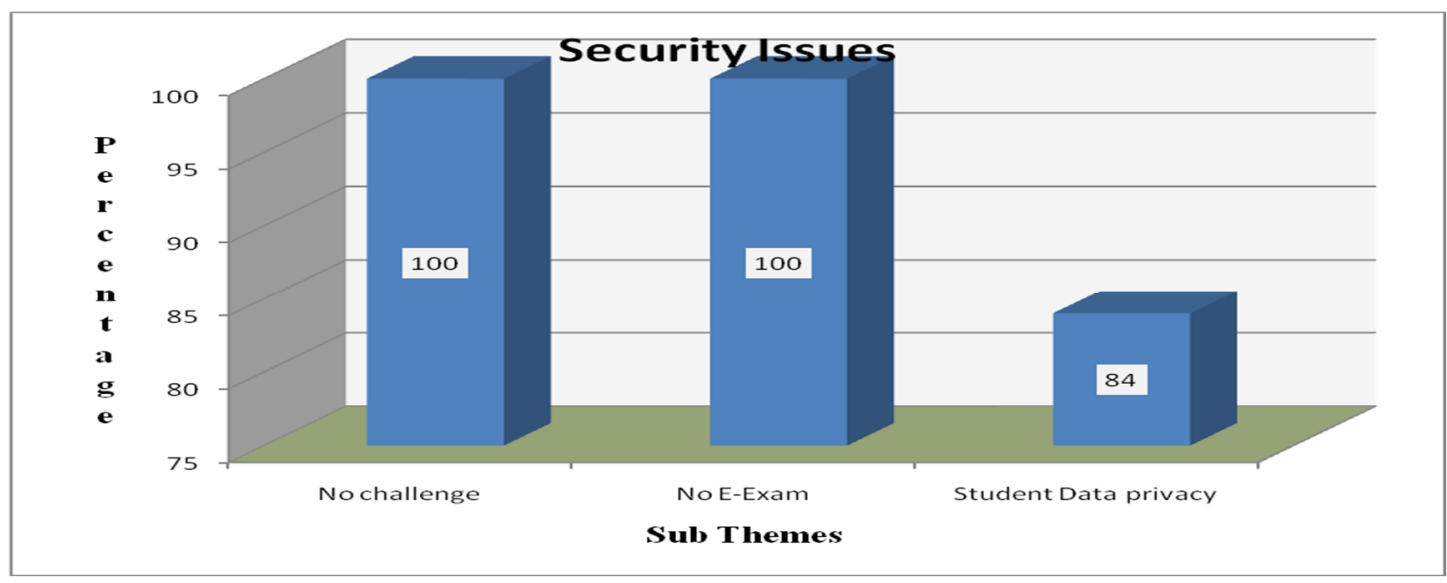

Q 10: To what extent you satisfied with the quality of online learning programme at your institution?

Graph 10 insists that significant majority (92\%) of respondents said that more bandwidth is required and $(84 \%)$ of the respondents indicated that there was need to improve the quality for distributed learning at AIOU. Majority of the respondents $(80 \%)$ reported that e-exam was needed for quality education in distributed learning and $68 \%$ of the respondents viewed that video interaction was required for effective distributed learning at AIOU.

Graph 11

Percentage of the respondents on quality of online learning programme

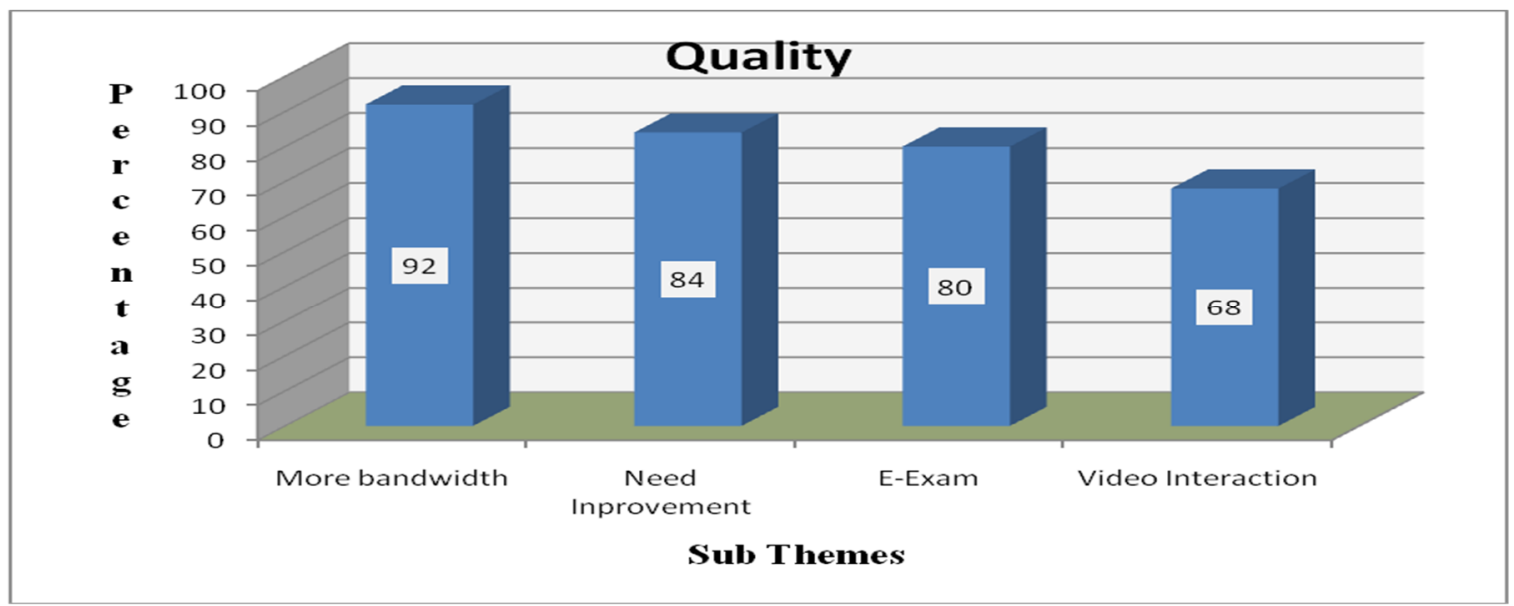




\section{Q 11: Do you think that faculty involved in distributed learning at AIOU needs training to use the network for effective learning?}

Graph 11 points out that $60 \%$ of respondents commented that training required to use the communication tools effectively and $52 \%$ informed that continuously training required as the technology is changing rapidly.44\%of the respondents indicated that there required ICT training required and only $36 \%$ viewed that pedagogical training was required for distributed learning at AIOU.

Graph 12

Percentage of the respondents on training to use the network for effectively

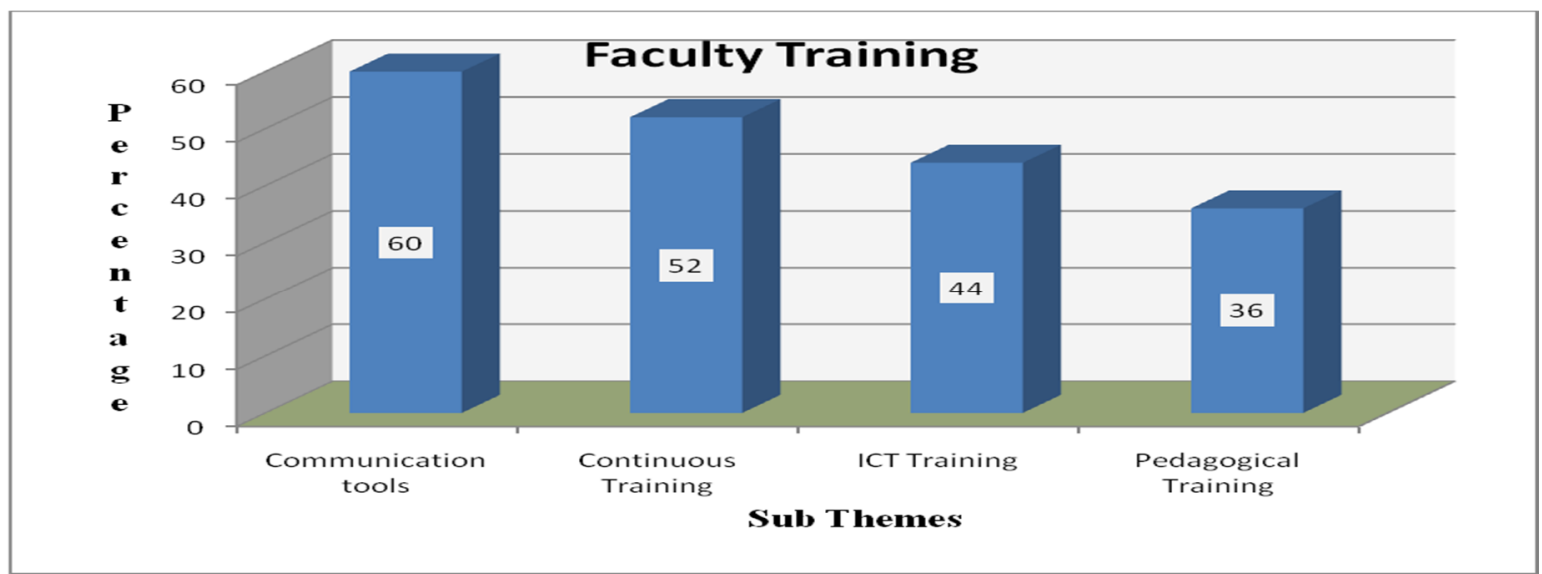

\section{CONCLUSIONS}

Organizational polices are in the favor, facilitating and supportive to implementation of the distributed learning. Tutors in the distributed learning environment are effectively utilizing the network facilities as sufficient information are provided on the network. The tutors function properly in the distributed learning setting and the learning environment support learning engagement and motivation to successful completion of the learning process. The distributed learning network supports all the tutors' academic activities and all kinds of asynchronous communications like blogging, wikis, mailing list, audio and video recorded tutorials and discussion forums to support the learning of the distant learners. Distributed learning network supports tutor to provide feedback and all collaborative activities.

Tutors face challenges to the synchronous learning activities like video conferencing and faceto-face feedback and whiteboard sharing due to the low bandwidth of the internet and the issue of the bandwidth is more significant. The distributed learning environment face issues in network management, network failure and difficulty in the remote access. These managerial and network issues create hurdles to the group interaction.

\section{RECOMMENDATIONS}

> The bandwidth may be increased at institutional level and standard of minimum bandwidth required to access the synchronous and asynchronous instructional activities may be conveyed to the remote users for effective outcome of the system in distributed learning. 
$>$ The network may be effectively managed to facilitate the instructional activities in distributed learning

$>$ The quality of the distributed learning programmes may be enhanced by focusing the different aspects like infrastructure, communication tools and techniques, eexam, collaborative communication facilities, interactive climate and academic support to learners

$>$ The comprehensive system of the feedback from faculty to the individual learners may be established to facilitate the divers learner in distributed learning

$>$ Continuous training of the faculty to design develops, organize and present the content keeping in view the convenience and mental engagement of the learners in the diverse climate of the distributed learning

\section{BIODATA AND CONTACT ADDRESSES OF AUTHORS}

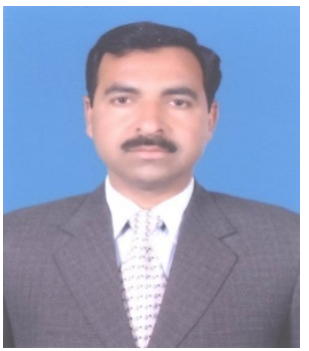

Qadir BUKHSH (1974\01\11) has been serving as Assistant Professor in the Department of Educational Training, The Islama University of Bahawalpur, Pakistan and joined this institution back in 2006. He has the work experience as a Community Mobilizer, Secondary School Teacher, Head Master and tutor of distance education in Allama Iqbal Open University Islamabad, Pakistan. He got couple of research trainings under the collaboration of Islamia University of Bahawalpur, SES Germany and IRA, USA. His areas of interest are distance education and literacy.

Qadir BUKHSH

Department of Educational Training, Faculty of Education

The Islamia University of Bahawalpur, Pakistan

Tel: 0092629255068

Email:qadir.bukhsh@iub.edu.pk or gadir iub@yahoo.com

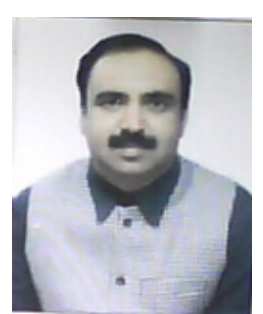

Muhammad Ajmal CHAUDHARY, PhD has been serving as Assistant Professor and Chairman Department of Distance, Non-Formal and Continuing Education at Allma Iqbal Open University Islamabad, Pakistan. He got master degree in education in from Indira Gandhi National Open University, New Delhi, India and PhD from National University of Modern Languages Islamabad, Pakistan. He joined Allama Iqbal Open University in 2007. He participated in more than fifteen professional development trainings organized by Allama Iqbal Open University with the collaboration of international and national academic organizations. He is HEC approved supervisor for $\mathrm{PhD}$.

Dr. Muhammad Ajmal Chaudhary

Chairman Department of Distance,

Non-Formal and Continuing Education

Faculty of Education Allama Iqbal Open University Islamabad, Pakistan

Phone: 0092519057707

Email:ch ajmal2003@Yahoo.com or drajmal@aiou.edu.pk 


\section{REFERENCES}

Ahmad.I \& Bokhari.U.M. (2013) Combine Effect of synchronous and a synchronous E-Learning on Distance Education, International Journal of Computer Science issue Vol. 10 Issue1, No. 1, pp 546-550

Baker. J.D \& Zuvela. D. (2013) Feed forward strategies in the first year experience of online and distributed learning environments, assessments, Evaluation in Higher Education, Vol. 38, No. 6, pp. 687-697

Barik. N \& Karforma. S.D. (2012) Risks and Remedies in E-learning system, international journal of network security \& its applications Vol 4 No. 1, pp 51-59

Ciftci. S et al. (2010) Attitude of distance education students towards web-based learning-a case study: Procedia of Social and Behavioral Sciences Vol.2 issue 2 pp 2393-2396

Cornell University Library. (2013) Tutorial, www.library. Corneu.edu/DL/tutorial/tul-2.html

Dutta. K. A el al .(2011) E-learning in Higher Education: Design and Implementation, international journal of computer science issues Vol 8. Issue No. 4 No. 2, pp 509-516

Kaewkiriya (2013) Framework for distributed E-Learning management system, Journal of Computers, Vol. 8, No. 7, pp 1635-1647

Liu. A et al. (2010) Innovation in construction education: role of culture in E-learning, architectural engineering and design management, Vol 6 issue 2, pp 91-102.

Mahfouth. A. (2012) The authentication Techniques in Distributed E-Learning between universities in Avicenna Virtual Campus Network, International Journal of Computer Science issue, Vol 9, Issue 3, No. 2, pp 418-422

Mshvidobadze. T \& Gogoladze. T (2012) About Wet-Based Distance Learning, International Journal of Distributed and parallel system (IJDPS) Vol.3 No. 3, pp. 133-143

Valle. D. R \& Duffy. M.T. (2009) online learning, learner Characteristics and their approaches to managing learning, Instructional sciences Vol 37 PP.129-149

Verdu. E el al .(2012) A distributed system for learning programming on-line, Journal of Computer \& Education Vol 58, Issue 1 , pp 1-10

Xenos. M et.al. (2009) Introduction of synchronous peer collaboration activities in distance course, IEEE Transaction, Vol. 52, No. 3, pp. 305-311 